\title{
Estado, autonomia e integração regional na América Latina
}

\section{State, autonomy and regional integration in Latin America}

\author{
Leonardo Granato* e Ian Rebouças**
}

Resumo: Neste artigo buscamos construir o conceito ampliado de autonomia estatal para, a partir dele, entendermos a integração regional como ferramenta fundamental para a superação do subdesenvolvimento e da dependência dos Estados latino-americanos. Para tanto, trabalhamos 0 Estado como regulador social do âmbito interno e como pertencente a um sistema internacional hierárquico, e, logo, condicionado a partir da posição que ocupa nessa estrutura. Aplicamos as abordagens discutidas nas seções anteriores para entendermos que tipo de Estado interventor seria 0 mais adequado para o desenvolvimento interno dos Estados latino-americanos. Construímos nosso conceito ampliado de autonomia, que emana da interligação das dimensões interna e externa defendida neste trabalho. Encerramos nosso trabalho argumentando a favor da relevância de entender a integração regional como instrumento de desenvolvimento interno e de inserção não subordinada dos países latino-americanos no sistema internacional.

Palavras chave: Estado; Autonomia; Integração Regional; América Latina.

ABSTRACT: In this paper, we aim to build an expanded concept of state autonomy in order to understand regional integration as a fundamental tool for overcoming underdevelopment and dependence on Latin American states. With this aim, we conceive the state as a social regulator of the internal scope and as belonging to an international hierarchical system, and therefore, conditioned by the position it occupies in this structure. We apply the approaches discussed in the previous sections to understand what type of intervening state would be most appropriate for the internal development of Latin American states. We construct our extended concept of autonomy, which emanates from the interconnection of the internal and external dimensions defended in this article. We conclude our work by arguing for the relevance of understanding regional integration as an instrument of internal development and non-subordinate insertion of Latin American countries into the international system.

Key words: State; Autonomy; Regional Integration; Latin America.

Recibido: 13 de julio de 2017

Aceptado: 10 de noviembre de 2017

$*$

Universidade Federal do Rio Grande do Sul (leonardo.granato@ufrgs.br).

** Universidade Federal do Rio Grande do Sul (reboucas.ian@gmail.com). 
INTRUDUÇÃO

integração regional na América Latina tem sido um desafio cons-
tante na história da região. Questões como a manutenção da
paz, o fortalecimento econômico e a preocupação com a política
intervencionista estadunidense na região se fizeram presentes nas agendas compartilhadas dos países da região em diferentes momentos históricos e com diferentes intensidades. Analisando em retrospectiva o século XX, encontramos na região diversas propostas integracionistas orientadas por interesses e objetivos concretos. O viés instrumental da integração regional não é à toa. A integração, assim como a cooperação, é um recurso político utilizado ao redor do globo para diversas funções como arranjos políticos, liberalização do comércio, cooptação política, dentre outros. Para o Terceiro Mundo, e para a América Latina em especial, a referida integração regional pode se configurar como ferramenta fundamental para a superação do subdesenvolvimento e da dependência em que se encontra historicamente a região. Para tanto, deve ser pensada e projetada para este fim.

Neste trabalho, propomos que a integração regional seja entendida como ferramenta para a autonomia e desenvolvimento dos Estados latinoamericanos. Para tanto, interligando as contribuições de autores como Poulantzas, Miliband, O'Donnell, Skocpol, Mann e Evans, adotamos uma abordagem bidimensional do Estado, como regulador das relações sociais internas e como constituinte do cenário internacional, atuando a partir de constrangimentos e brechas sistêmicas. Esta abordagem permite entendermos a necessidade de um Estado forte em ambos os contextos - penetrador e relevante na esfera interna, autônomo na esfera externa. Em um segundo momento, buscamos entendermos as contribuições genuinamente latino-americanas de autores como Furtado, Jaguaribe e Puig, que defendem que o desenvolvimento da autonomia estatal, alcançado principalmente através da integração regional, é primordial e necessária para a superação da dependência e vulnerabilidade externas que atravessava (e ainda atravessa) a região latino-americana. 
Emana naturalmente da bibliografia analisada durante o trabalho a necessidade de debatermos os distintos conceitos de autonomia estatal utilizados pelos autores estudados. Parece deveras adequado que, a partir do diálogo entre os autores mencionados, possamos propor um diálogo também entre as visões distintas de autonomia, unificando as autonomias internas e externas, e encontrando assim um conceito ampliado de Autonomia, utilizando a letra maiúscula para diferenciá-la dos demais usos. Dessa forma, na abordagem bidimensional do Estado, Autonomia, conforme abordado na terceira seção, será a chave tanto para a libertação interna quanto a externa, sendo, assim, adequado seu uso ao objetivo aqui proposto.

O que se pretende com o referencial teórico aqui proposto não é o ineditismo ou a construção de uma nova teoria do Estado. Julgamos que os autores aqui utilizados, a partir do momento que postos em diálogo, podem propiciar uma leitura que implica novas maneiras de entender a integração regional, adequadas ao caso latino-americano. Trata-se de uma tentativa inicial de construção de uma abordagem e, portanto, suscetível, temos certeza, às limitações próprias advindas de todo ecletismo teórico.

\section{O ESTADO COMO REGULADOR SOCIAL}

Nesta seção, iniciaremos a proposta de diálogo, partindo do entendimento de diferentes autores quanto ao papel do Estado na sociedade. Entender de que modo essas visões convergem e se distanciam, no que diz respeito a nosso conceito-chave de autonomia, nos aparenta ser fundamental ponto de partida.

Para autores como Poulantzas (2007), Miliband (1972) e O'Donnell (1978: 1157-1199), o Estado tem o fim último de reproduzir o modo de produção capitalista. Nesse seu objetivo, o Estado pode adotar medidas e políticas que não satisfaçam diretamente as elites econômicas no curto prazo, tendo em vista um fim de longo prazo correspondente à perduração do modo de produção capitalista. Isso nos permite afirmar que o 
Estado capitalista, a partir dessa abordagem teórica, possui autonomia em relação às elites. De maneira similar, autores como Skocpol (1984) e Mann (1984: 185-213) entendem que o Estado não é mero reflexo de demandas de classe, logo, tampouco é controlado pelo interesse das elites econômicas. A autonomia do Estado é potencial, e referente às capacidades estatais de planejamento e perseguição de objetivo político (Ianoni, 2013). O que diferencia basicamente as duas visões de autonomia é que para a primeira a regulação da sociedade, realizada a partir da autonomia estatal, não é feita de forma neutra, tendo por objetivo a reprodução do modelo capitalista; já a segunda entende como uma regulação não determinista a priori, cujos viés e objetivos regulatórios dependerão do projeto sócio-cultural-político do Estado em determinado momento (Rey 2014: 115-139). A autonomia trabalhada pelos referidos autores diz respeito à parcela da classe dominante, opondo-se, portanto, a visão marxista clássica do Estado como instrumento da elite detentora dos meios de produção. O esclarecimento da distinção entre o que entenderemos aqui por classes dominantes e elites é fundamental para o desenvolvimento de nosso argumento.

Para Miliband (1972), as sociedades capitalistas avançadas possuem uma pluralidade de elites econômicas, constituindo diversos grupos e interesses que afetam o processo político. Pensemos aqui em diferentes grupos capitalistas, detentores de distintos monopólios, seja na indústria automobilística, de alimentos, ou grandes proprietários rurais. São grupos distintos com interesses distintos. Contudo, dentro desta elite, há uma classe econômica que se sobressai, com objetivos e interesses coesos, que podemos chamar aqui de "elite" da elite econômica, dotada de poder econômico. Da mesma forma, na esfera pública do Estado, há a conformação de uma elite estatal, dotada de poder estatal, que se sobressai dentre o universo ampliado de políticos, burocratas, militares, juízes, e assim por diante. A classe dominante será conformada, portanto, pela elite da elite estatal e pela elite da elite econômica, unindo os dois campos em um grupo com posicionamento privilegiado na hierarquia social. Essa classe dominante, quando observada em atuação no campo político, pode passar a impressão de diversidade de ideias e de conflitos de interesses, seja 
quando políticos distintos disputam por partidos diferentes ou quando empresários do mesmo setor, digamos, bancos privados, apoiam campanhas distintas. Contudo, ambas as elites concordam em uma questão fundamental: não está em jogo o fim do capitalismo. Entendemos, assim, que a configuração do sistema político, das elites e classes dominantes e, portanto, do Estado, preza pela reprodução do modelo capitalista como fim último, conforme apontado pelo autor em questão.

Justificamos essa visão ao apontar a noção de que alguns governos podem adotar políticas assistencialistas e de redistribuição de renda, que teoricamente vão de encontro aos interesses capitalistas. Contudo, políticas ou concessões como as supracitadas são os chamados "falsos sacrifícios" (Poulantzas 2007), que visam ao fim e ao cabo a reprodução do modelo. Se analisarmos as supracitadas políticas, por exemplo, entende-se que essas medidas visam a dotar as populações marginalizadas e carentes de poder de compra que até então não possuíam. Elas serão inseridas na sociedade através do consumo, fortalecendo assim todo o sistema.

Para Poulantzas, a atuação estatal capitalista tem como objetivo a conservação dessa configuração, dessa relação de classes presente no modo de produção capitalista, de modo a corresponder aos interesses políticos da classe dominante. A função global do Estado é a coesão e a mediação das relações sociais visando a preservação do sistema. Esta coesão de diferentes classes, obedecendo à mesma ordem centralizada, afeta inicialmente $\mathrm{o}$ nível econômico, ao mediar as relações de trabalho na sociedade. O poder institucionalizado do Estado emana, dessa forma, das estruturas políticas de um modo de produção e de uma formação social. É importante frisarmos que o Estado não deteria poder por si só, mas os detentores de poder seriam as classes sociais, sendo o Estado o centro do exercício de seus poderes políticos. Assim, nessa visão, não se pode desprender Estado de sociedade para a análise do Estado capitalista.

A visão de O’Donnell (1978) é também a de um Estado com papel fundamental nas relações sociais internas, e nos serve para aprofundarmos melhor a função do Estado imbricado nas relações sociais. Para o autor, o Estado seria o componente político das relações de dominação exis- 
tentes em um território determinado. Esta dominação se daria através de dois instrumentos, coerção e ideologia. A principal relação de dominação na sociedade capitalista seria justamente entre o detentor dos meios de produção, empregador, e o trabalhador assalariado, empregado. Nessa relação assimétrica, o trabalhador não possui os meios de produção, por isso depende do empregador, enquanto que este não possui os meios de coerção, para fazer com que o trabalhador lhe obedeça. É nesse momento que surgem as instituições estatais nas relações sociais: leis trabalhistas, ordenamento jurídico, direito à propriedade privada, dinheiro, dentre outras. O Estado respalda a relação social de exploração do trabalhador, e dessa forma surge como expressão geral de um interesse particular, como visto anteriormente em Poulantzas e Miliband. É essa relação social que o Estado sustenta e articula de maneira desigual e contraditória (O'Donnell 1978) o que não é percebido por todos. Ponto fundamental da dominação ideológica estatal é emascarar o fato de que determinadas relações sociais, como as descritas acima, são conflituosas.

Para O'Donnell, um Estado forte é aquele que estabelece com eficácia a lei e que não é percebido pela população como âmbito de perseguição de interesses particularistas. Em oposição, um Estado fraco teria leis pouco eficazes, que não penetram e não alcançam toda a população/ território (1993: 163-184). Tal dualidade nos conecta com a noção de poder infraestrutural de Mann (1984), conceito que nos permitirá entender as formas positivas (adotando-se as camadas subjugadas da sociedade como referencial) com que o Estado pode afetar as relações sociais.

Segundo o referido autor, o Estado é primordialmente um regulador das relações sociais (Mann 1984). Dessa forma, o autor entende que a autonomia do Estado se dá em relação às principais agrupações de poder da sociedade civil, ou seja, em relação à classe dominante —não necessariamente com o fim último de reprodução do modelo capitalista. A visão de Mann sobre o Estado é ao mesmo tempo de enxergá- lo como "arena" e como "ator": seria um espaço onde as relações sociais são reguladas, a partir do momento que essa condição é a fonte de sua autonomia (Mann 1984). É apenas na figura das elites estatais que o Estado pode ser visto 
como ator, que age racionalmente e é dotado de autonomia organizacional. Essa racionalidade, presente de certa forma na visão marxista, quando o Estado perseguiria, racionalmente, os fins de reprodução capitalista, se manifesta segunda Mann (1984) na sua distinção das formas do poder estatal.

Para o autor, o poder estatal pode ser dividido em poder despótico e poder infraestrutural (Mann 1984). O primeiro é típico do Estado absolutista e é caracterizado por ações que não necessitam de negociação com a sociedade civil. Nesse caso, a elite estatal está acima da referida sociedade e agirá de maneira autoritária. O segundo, típico dos Estados capitalistas modernos, trata da capacidade do Estado em penetrar na sociedade civil e pôr em execução as decisões políticas por todo o território. O Estado tem a função de coordenar, dentro de sua estrutura, as atividades da sociedade civil. Esse poder é mais próximo do conceito de capacidades estatais que utilizaremos mais adiante, na segunda parte deste trabalho. Entendemos aqui, a partir dessas contribuições de Mann, que o Estado age racionalmente ao buscar que forma de poder utilizar - entendendo não ser adequado passar por cima das negociações com a sociedade civil, o Estado deixa de utilizar o poder despótico e passa a dar brecha para demandas sociais de políticas públicas condizentes com as necessidades da sociedade e do próprio Estado.

Dessa forma, os Estados fortes são aqueles dotados de capacidades estatais tais que penetram e implementam políticas por todo o território adequadamente, possuindo assim significativo grau de poder infraestrutural. Já os fracos não penetram a sociedade e acabam criando zonas periféricas, que terminam por desenvolver leis próprias, relações patrimonialistas e isolamento, o que impede uma adequada mobilização da sociedade civil, tornando assim o subdesenvolvimento e o isolamento em um ciclo vicioso (O’Donnell 1993).

Nesse processo de ação estatal penetrante na sociedade, Oszlak (2007: 115-142) aponta que a sociedade também tem papel de pautar a relação Estado e sociedade e consequentemente essa ação estatal. Nesse sentido, para Oszlak e O’Donnell (2007: 555-587), a política estatal é, por definição, um conjunto de iniciativas e respostas que observadas em 
um determinado contexto político e histórico permitem identificar a posição predominante de um Estado em relação a questões que emanam da sociedade. A necessidade do Estado para dar voz a essas demandas da sociedade é evidente: na América Latina, por exemplo, o Estado aparece como única instância capaz de mobilizar recursos e criar condições que permitem superar os graves problemas sociais encontrados no interior de cada país. Contudo, chegamos aqui a um ponto importante de nossa argumentação e construção teórica: não é apenas o âmbito interno que define as possibilidades e margens de manobra da ação estatal.

\section{O ESTADO CONTRANGIDO INTERNACIONALMENTE}

Dando continuidade ao diálogo teórico proposto, adentramos, nessa seção, na questão da hierarquia do sistema internacional e na problemática que emana da posição ocupada por um país nesta estrutura. Para Skocpol (1984, 1985), o Estado como conjunto de organizações administrativas, políticas e militares, encabeçadas por uma autoridade executiva, não é mera arena, mas constitui um ator, potencialmente autônomo, que influencia a sociedade e dá forma a processos políticos e sociais. Acrescenta-se a isso o fato de o Estado não poder fugir de sua sina em estar inserido em um sistema internacional, composto por diversos outros Estados nacionais e disposto de maneira hierárquica. Dessa forma, para a autora, o Estado colhe e planta, no sistema internacional, condicionantes para sua atuação. A posição nesse sistema implica, nessa abordagem, condições e pressões sob o Estado, o que influencia em seu comportamento e, logo, em suas margens de políticas não só externas, como também internas (Skocpol 1984). Assim, é na interação entre conflitos sociais internos e pressões externas que atua o Estado autônomo, onde os funcionários executivos buscam recursos e constroem organizações administrativas condizentes com o ambiente interno e as possibilidades da conjuntura internacional.

Com similar visão, Gourevitch (1978: 881-912), na tentativa de estabelecer o internacional e o nacional como mutuamente causais do com- 
portamento estatal, indica que são dois os principais tipos de condicionantes internacionais para a política doméstica: a distribuição de poder entre os Estados e a distribuição de riqueza no sistema internacional, ou divisão internacional do trabalho. Dessa forma, as estruturas internacionais, através dos condicionantes de poder e de riqueza, indicam os limites de atuação dos governos.

Ninguém mais apropriado para falar dessa temática do que os estudiosos do Terceiro Mundo, renegados à condição de periferia do mundo desde os movimentos de expansão marítima dos Estados europeus que datam dos séculos XV e XVI. Em uma clássica obra da década de setenta, O’Donnell e Linck (1973) preocuparam-se em teorizar a questão da autonomia como contraponto da dependência. Para os referidos autores, estar em uma posição de "dominante" significa ter acesso a determinados recursos que o dominado não tem, e é a partir da coerção e do controle ideológico envolvido na dominação que o dominante buscará a inação do dominado, ou seja, que ele não inove, aceite o status quo e não atue por temor de sanções ou repreensões. Essa relação de dominação tanto vale para as dominações de classe no âmbito interno, como já foi visto aqui, quanto para a hierarquia e desigualdade do sistema internacional.

Segundo ampla literatura, a América Latina esteve em condição de dependência no sistema internacional durante todo o século XX, e essa posição em grande parte se deve à atuação dos Estados Unidos como potência hemisférica durante parte do período (Jaguaribe 1972, 1973; Cardoso e Faletto 1973; Furtado 1968; Puig 1986; O’Donnell e Linck 1973). Concorda-se, a partir disso, que o desenvolvimento dos países latino-americanos não pode simplesmente resultar de vontade política interna ou de forças do mercado (Furtado 1968), dado o amplo acesso a recursos de poder e de riqueza dotados pelos países do centro, em especial pelos Estados Unidos. Fortalece a condição de dependência o fato de que essa divisão internacional do trabalho, que hierarquiza o sistema internacional, tem caráter conservador e, como já dito, de manutenção do status quo: cada país contribui com a dinâmica global a partir do que produz, e não existem incentivos para que se quebre essa lógica (Evans 2004). 
Além disso, a dependência externa está enraizada nas sociedades latino-americanas. Suas elites, que se beneficiam das correntes regras do jogo, atuam para a manutenção do sistema. Toda a organização das classes sociais e produtivas internas está estruturada a partir dessa condição subordinada no âmbito externo, conforme o estudo de Cardoso e Faletto (1973). Nesse sentido, as noções de autonomia e desenvolvimento do Estado periférico estariam aliadas a uma necessidade de reestruturar a sua ordem interna: nas palavras dos referidos autores se necessitariam "alterações no sistema social de dominação e a redefinição das formas de controle e organização da produção e do consumo" (Cardoso e Faletto 1973: 25). Por sua parte, O'Donnell e Linck (1973) também reforçam a necessidade de modificação dos padrões de consumo, de valores e de redistribuição de poder internamente, para se superar a condição de dependência. Segundo os autores, as disputas internas dos Estados latino-americanos, nesse contexto, se caracterizam por disputas para saber quem negociará a dependência, e não a redefinição dessa mesma dependência.

Como resulta possível afirmar a partir do exposto, a condição de subdesenvolvimento e dependência dos Estados latino-americanos encontra causas e consequências tanto nas conjunturas externas e internas. A visão "bidimensional" do Estado que aqui estamos retratando possibilita a leitura das relações sociais internas ao Estado e as formas em que elas estão dispostas, ao mesmo tempo em que entende que o Estado, inserido no contexto internacional, sofre constrangimentos e pressões no universo do que the é permitido. Mais do que isso, a abordagem bidimensional relaciona esses dois âmbitos e encontra pontos onde condições e características de um âmbito reforça o outro.

\section{O ESTADO INTERVENTOR E TRANSFORMADOR}

Ao propormos um modelo de Estado interventor e transformador como alternativa aos problemas estruturais enfrentados pelos Estados latino-americanos, faz-se útil a análise de Oszlak (2007) sobre os processos de formação 
e construção dos Estados na região, constituída de dois processos. De um lado, tal qual o clássico movimento de formação do Estado europeu apresentado por Tilly (1996), há o desenvolvimento dos aparatos de repressão e regulação da ordem interna, bem como a regulação da acumulação de capital social básico. Nesse primeiro momento, são também criados os mecanismos legislativos e organismos públicos voltados para resolver os problemas de ordem e progresso, apontados por Oszlak (2007) como problemas típicos do momento de formação do Estado latinoamericano. Do outro lado, há o desenvolvimento paralelo de uma capacidade extrativa e um aparato de arrecadação fiscal e administração financeira, o que asseguraria a reprodução do aparato estatal e a expansão econômica. Assim, para o autor em questão, o Estado na região constitui-se como agente ativamente atuante no processo de acumulação de capital, o que permite que este atue com fins de dinamizar os circuitos econômicos e contribuir para aumentar o excedente social, a serviço, cada vez mais, da dívida pública.

O que temos aqui é que o Estado latino-americano é agente interventor e transformador desde o momento de sua formação. A sua atuação é direta nas relações de acumulação de riquezas na sociedade, seja como regulador das relações de sociais, seja como ator autônomo das classes dominantes, visando apenas ao fim geral de reprodução do modo de produção capitalista. Nesse contexto, julgamos natural que a busca por alternativas para a superação do subdesenvolvimento e da condição de dependência parta justamente de uma atuação estatal voltada para esse fim. Cabe, também, ressaltarmos que a intervenção, por si só, não é algo necessariamente positivo para a população. Sendo interventor, o Estado atua e tem controle na regulação das relações de classe, o que pode resultar em benefícios ou opressões para as classes subjugadas. Os anos de subdesenvolvimento que remetem aos períodos de independência, bem como os anos de repressão popular e aumento de desigualdades sociais durante os períodos de ditaduras militares na região, são claros exemplos de Estados negativamente interventores, quando atuam não para a superação do subdesenvolvimento, mas para uma ampliação da brecha existente entre as classes produtoras e trabalhadoras, exploradoras e exploradas. 
Na busca por modelos alternativos de intervenção estatal, que buscam a superação do subdesenvolvimento e uma inserção não subordinada dos Estados latino-americanos no sistema internacional, podemos partir dos postulados de Furtado. Nesse sentido, o autor entende que a verdadeira revolução latino-americana trataria de quebrar a lógica da dependência externa a partir da revisão das disposições das classes no âmbito interno. Como as elites desses países estariam vinculadas à manutenção do status quo, ir de encontro à atuação desses grupos dominantes seria um fato "revolucionário" por si só. Seria preciso um esforço para criar instituições políticas capazes de superintender as mudanças sociais necessárias ao desenvolvimento. Assim, não se trataria apenas de uma revisão da posição das classes, mas do surgimento de organismos estatais que adequadamente internalizem e supram as demandas das classes populares. Logo, o autor indica que o princípio de nacionalidade, como a formulação de um interesse nacional que fosse superior aos interesses das classes dominantes e, portanto, autônomo, seria vital para os países subdesenvolvidos da região. Nesse sentido, o desenvolvimento seria tido como o grande projeto político do Estado (Furtado 1968).

Para alcançar esse nível de autonomia, que O’Donnell e Linck (1973) vão chamar de "autonomia nacional", seria necessária uma aliança dos diversos setores da sociedade, que pode partir inclusive do descobrimento de que todos possuem interesses em comum (e que poderiam se beneficiar de) com o fim da condição de dependência. Como já vimos, esse descobrimento quebraria a lógica induzida e ideológica da dominação, desnaturalizando a dependência e sendo possível, portanto, aspirar a sua superação.

Segundo Furtado (1968), portanto, caberia ao projeto político de desenvolvimento o desenho de uma estratégia para modificar a estrutura econômica e social do Estado. Esse plano estratégico de desenvolvimento deveria ser operado por uma sociedade consciente, sendo respaldado nas instituições do Estado, criadas para operacionalizar suas demandas. Para o autor, esse "movimento" rumo ao desenvolvimento exige de maneira paralela: crescimento da demanda geral por serviços, por parte da sociedade, e crescimento da atuação do Estado, e da sua autonomia, em prover 
esses serviços. Essa ligação é lógica, pois "as funções que a sociedade atribui ao Estado estão intimamente vinculadas com o sistema de poder que torna viável a ação desse mesmo Estado" (Furtado 1968: 116).

De forma semelhante, com abordagem voltada para a necessidade de um concerto interno, Guerreiro Ramos (1957) desenvolve o conceito de poder nacional. $\mathrm{O}$ autor parte da premissa de que o Estado latino-americano, preso na condição de dependência e de subdesenvolvimento, existe para a reprodução de uma lógica de dominação, representada em poderosa afirmação: "o Estado foi uma espécie de artefato sociológico, montado sobre nosso território para contestar e tornar possível o exercício de poder pela antiga classe dominante" (Guerreiro Ramos 1957: 18). Diante disso, o referido autor atribui um papel fundamental ao nacionalismo na árdua tarefa de buscar o desenvolvimento, sendo necessária a difusão da ideia nacionalista de que se deve trocar o estrangeiro pela produção para si mesmos. Guerreiro Ramos (1957) desenvolve, então, o conceito de poder nacional muito vinculado a essa ideia nacionalista, constituindo-se esse como a suprema instância normativa necessária para o encaminhamento do processo emancipatório do Estado dependente. Por sua vez, o autor vincula o poder nacional ao âmbito externo quando entende que a política externa de um país deve ser utilizada de maneira instrumental para o seu desenvolvimento, defendendo os interesses nacionais nos grandes acontecimentos da política e das relações entre os Estados.

Nesse mesma linha, Furtado (1968) vai elencar que o planejamento do Estado com fins desenvolvimentistas vai depender de um alto nível de integração da sociedade; da estrutura de poder e funções que a sociedade delega ao Estado (leia-se, autonomia); do grau de eficiência do governo como instrumento operativo do Estado; e das demandas do setor externo por produtos nacionais. Dessa forma, a partir dessas condicionantes, temos um panorama geral do que o Estado atuante, segundo o autor, deve buscar: integração e harmonia social interna; autonomia, a partir de estruturas burocráticas que absorvam as demandas sociais adequadamente e as transforme em serviços; desenvolvimento de capacidades estatais, conceito ligado ao poder infraestrutural do Estado, que deve penetrar a sociedade 
na implementação de políticas públicas; e coesão com o contexto externo, respeitando ou criando demanda externa.

Grande defensor da atuação estatal na promoção do desenvolvimento, e de certa maneira dos objetivos estatais supracitados, Evans (2004) vai nos proporcionar uma visão economicista-desenvolvimentista, indicando que o desempenho econômico do Estado é uma terceira função deste, para além da defesa externa e da organização interna. Dessa forma, há de se desenvolver um papel transformador para o Estado ser capaz de gerar e acumular capital e de envolver-se nos conflitos de redistribuição de renda e bem-estar social. O Estado, dessa forma, deve ser atuante, presente nas relações sociais. Contudo, condizente com o que já foi desenvolvido nesse trabalho, o desenvolvimento dependerá de brechas estruturais e de um rearranjo das hierarquias internacionais, dado o caráter conservador da divisão internacional do trabalho.

\section{O CONCEITO AMPLIADO DE AUTONOMIA}

A partir do diálogo com os autores nas seções anteriores, temos visto como a autonomia relativa do Estado tem sido interligada à ideia de um Estado que seja independente da classe dominante, bem como capaz de implementar de forma efetiva políticas públicas condizentes com os desejos e necessidades da sociedade civil. Conforme o intuito desse trabalho, agora pretendemos ampliar o seu uso, unificando duas visões de autonomia. Diferenciaremos esse conceito ampliado de Autonomia ao utilizar a letra maiúscula.

A primeira visão, já comentada na primeira parte deste trabalho, pode ser aqui recapitulada rapidamente pelo que escreve Ianoni (2013). A partir da noção de que o Estado seria ator regulador autônomo da sociedade (visão do institucionalismo histórico) ou dirigente-regulador autônomo da sociedade (rumo à reprodução do capitalismo, visão marxista), a autonomia emanaria do não controle do Estado pelas elites econômicas. A partir dessa autonomia, o Estado conseguiria perseguir, partindo de um 
equilíbrio e arranjo interno, o desenvolvimento a partir de demandas sociais, efetivamente internalizadas por organismos burocráticos institucionais adequados e abertos a pautas populares.

Tudo o que já foi dito até aqui continua valendo para nós, mas é importante frisar que o discutido até o momento se referia a uma autonomia estatal dada a partir do âmbito interno das disputas de poder entre as classes sociais fundamentais. Nesse sentido, o conceito ampliado de Autonomia vai não somente abranger esse viés interno, como também se estender ao âmbito externo e à ideia de desenvolvimento autodirecionado.

A segunda visão de autonomia que compõe o nosso conceito ampliado parte das contribuições de autores latino-americanos como Puig e Jaguaribe. Bem nos moldes e limites que aqui trabalhamos, buscando alternativas dentro do Estado capitalista moderno, Jaguaribe (1973) entende que uma vez que se desconsidera a "revolução" como alternativa, resta a busca pela "autonomia". Esta última abarcaria a noção de uma política externa construída de acordo com os interesses do país e a partir das margens de atuação internas e externas à disposição. A autodeterminação de seu próprio desenvolvimento parece ser uma ideia norte do conceito para Jaguaribe. Para se alcançar a autonomia, o autor propõe um modelo autônomo de desenvolvimento e integração latino-americana, entendendo assim a integração como um meio para se alcançar o fim autonômico. Deixemos para desenvolver melhor o modelo de integração proposto por Jaguaribe na seção seguinte.

Por sua vez, Puig entende a autonomia de modo similar ao autor brasileiro. Para o autor argentino, a autonomia seria a capacidade de decisão própria que se pode ter, levando em conta os condicionantes do mundo real (Puig 1980). Para tanto, seriam necessárias condições que indicassem viabilidade (recursos mínimos) e elites comprometidas com o projeto de autonomia (1980: 148). Assim como Jaguaribe, Puig (1986) entende que a integração regional é condição necessária para que os Estados latino-americanos alcancem autonomia, destacando a importância de estratégias comuns nas mais variadas áreas de política governamental. 
O que se percebe entre os dois autores é uma semelhança em suas definições de autonomia: indicam a relevância das conjunturas reais e possíveis, internas e externas, para se traçar o projeto político de autonomia, e concebem a integração regional como um meio para se alcançar esse objetivo. Colacrai (2009) entende essa autonomia, trabalhada por Puig e Jaguaribe, como um esforço em se reconhecer o Estado periférico como ator, e não como objeto, nas relações internacionais. A autora indica que, à luz do pensamento dos referidos autores, estratégias como a integração regional deveriam estar voltadas para o reforçamento das capacidades estatais de atuação no meio internacional, diminuindo assim a dependência em relação ao centro (Colacrai 2009: 33-49). Dessa forma, por mais que tivessem como fim o desenvolvimento do Estado para posterior ampliação do bem-estar das populações, as noções de autonomia desenvolvidas por Puig e Jaguaribe estavam mais voltadas à atuação externa do Estado, e a integração regional como instrumento de desenvolvimento e autonomia é prova disso.

O que queremos propor aqui, então, com o conceito ampliado de Autonomia, é a unificação em um só termo das noções de autonomia relativa (referente ao âmbito interno e em relação às classes dominantes, o que lhe permite uma direção de acordo com demandas sociais, sem perder o fim último de reprodução do modelo capitalista), e de autonomia decisória segundo Puig e Jaguaribe, que requer o alinhamento das políticas externas dos países periféricos em prol da integração regional, meio que por sua vez reforçaria as capacidades estatais para o desenvolvimento interno, garantindo a tentativa de superação da condição de dependência externa. Como é claro, alguns pontos das duas noções são recorrentes, o que justifica e reforça a união das duas noções em um só conceito ampliado e mais robusto: o Estado dotado de Autonomia é interventor e transformador social a partir de um projeto político próprio e independente das classes dominantes, bem como possui externamente capacidades de atuação independente de alinhamentos políticos, econômicos ou ideológicos com relação aos centros hegemônicos de poder, sendo capaz de formular sua própria agenda e perseguir seus interesses. Está embutida nessa noção de 
Autonomia o desenvolvimento de instituições estatais dotadas de mecanismos de absorção de demandas populares, para fins de compor a agenda do Estado, em uma espécie de interesse nacional legítimo. Assim, a partir do fortalecimento dessa Autonomia, e tendo esta como objetivo, pode-se dizer que o Estado se fortalece como provedor de bens públicos e serviços sociais para sua população, bem como desenvolve condições para superar o subdesenvolvimento e a condição de dependência.

Outro ponto que emerge desse conceito ampliado de Autonomia é a importância do estudo das capacidades estatais. Com diferentes abordagens, o conceito de capacidade estatal como "as possibilidades que o Estado tem para alcançar, na prática, a implementação das políticas públicas que se propõe, de forma a afetar efetivamente a realidade social" (Rey 2014: 117), foi objeto de tratamento teórico e empírico por diversos autores, conforme retratado em Cingolani (2013). Pelas inúmeras dimensões envolvidas que não serão aqui detalhadas, basta apenas sublinhar que o conceito incorpora variáveis políticas, administrativas, técnicas e institucionais. Como indica Rey (2014), a própria definição de capacidades estatais, que inclui uma dimensão política, indicia a natureza relacional entre elites dirigentes estatais e a população, sendo esta última necessária e considerada nos processos de tomada de decisão. Neste sentido, deixamos de entender a formulação de políticas como mero acordo entre as elites, e reforçamos a noção de uma população dotada de poder de agenda.

Para finalizarmos a presente seção, é importante também, ao utilizarmos o conceito ampliado de Autonomia, entendermos a política externa como uma política estatal, adentrando, portanto, nas considerações de capacidades estatais. Segundo Granato, Oddone e Battaglia (2016), se a política externa fosse vista dessa forma, e com viés autonômico, transformar-se-ia em instrumento de desenvolvimento interno (tendo a integração, tal qual os ditames clássicos, papel instrumental). Utilizando a mesma linha de pensamento em nosso conceito ampliado de Autonomia, pensar a política externa como uma política pública nos possibilita entender a referida política também como ferramenta não só de desenvolvimento interno, mas também de superação da dependência e de vulnerabilidade externas. 
O ESTADO INTEGRADOR REGIONAL

Unificadas as duas noções de autonomia que emanam da abordagem do Estado regulador social (âmbito interno) e do Estado condicionado no âmbito externo em um conceito ampliado de Autonomia, damos início a nossa última seção. Entendemos aqui a integração regional como amplo instrumento com fins desenvolvimentistas, sendo necessário, portanto, a formulação de uma política comum entre governos nacionais (Furtado 1968). Esse fim desenvolvimentista fica claro na explanação de quais devem ser os objetivos da integração segundo Jaguaribe, sendo eles: desenvolvimento nacional, maximização nacional e regional da autonomia de decisões, e maximização da endogenia do desenvolvimento e da viabilidade regional. Assim, o autor entende que a integração acarretará na construção de um grande fundo de recursos humanos, tecnológicos, naturais e financeiros, compostos pelos países interessados nessa integração (Jaguaribe 1973). Podemos notar que a obtenção de recursos é fundamental para a superação da dependência ao entendermos que a dependência de hoje é sustentada, pelo menos em grande parte, pela ausência de recursos por parte dos dominados e pelo monopólio de recursos por parte dos dominantes.

De maneira ampliada, Puig indica a importância de uma concepção integral da integração regional, não se limitando ao âmbito econômico-comercial, mas de viés também político, cultural e social. Assim, a integração bem-sucedida e condizente com os interesses autonômicos deve ir além dos Estados e das elites, devendo penetrar a sociedade e se fazer presente no impacto das vidas das populações (Puig 1986). Sendo assim, vontade política é necessária para a integração, mas não suficiente, sendo também necessária a cooptação das populações, o que deve ser feito através de políticas efetivas e com impacto no todo social. Acima de tudo, a integração regional para Puig (1986) deve ser baseada na solidariedade, flexibilidade e gradualidade, o que se mostra adequado às realidades latinoamericanas marcadas pelas assimetrias de poder e pelos processos de "conquista" das populações.

Percebamos como o modelo bidimensional por nós defendido é adequado para essa leitura. O Estado latino-americano que se integra 
busca, nesse instrumento, o impacto positivo na vida de suas populações. Almeja concertos políticos e políticas regionais que melhorem as condições econômicas e sociais dos seus povos. O esforço conjunto de se integrar reúne recursos antes exclusivos a um só Estado, compartilhando-os e gerando consequências não só exclusivas a este, mas a todos os envolvidos. Esse modelo só é possível se entendermos o Estado dotado de Autonomia, mediando nos interesses das classes dominantes no âmbito interno (o que impediria que a integração seja utilizada, apenas, com fins elitistas e excludentes), e livre de uma integração "satelizada", onde não haveria a união dos recursos dos Estados latino-americanos, mas uma integração que serviria para o controle e cooptação por parte do centro hegemônico desenvolvido (Jaguaribe 1973).

Nesse sentido, é possível entendermos a integração regional, sendo parte da política externa autonômica de um Estado, como política pública, uma vez que gera efeitos nas populações nacionais e parceiras, diferenciando-se no fato de que sua contraparte não é um cidadão, mas um outro Estado que possui interesses próprios (Granato 2015, 2016). Evidentemente, ao pensarmos a integração no que foi proposto até aqui, os interesses dos Estados seriam comuns e convergentes, ainda que não isenta de conflitos, o que facilitaria a implementação dessa política pública no que diz respeito à sua contraparte. Para o controle de que esses interesses similares se mantenham convergindo, cabe a construção institucional de organizações regionais, dotadas de mecanismos institucionais onde se canalizam as diferenças e conflitos entre os mesmos, necessárias nas tentativas de integração regional assistidas ao redor do globo.

$\mathrm{Na}$ América Latina, sabemos que inúmeras foram as instituições que propunham a integração regional com os mais distintos (e conflitivos) interesses e objetivos. Granato, Oddone e Battaglia (2016), ao analisarem as principais organizações atualmente vigentes na região, concluem que processos como o Mercado Comum do Sul (MERCOSUL), a União Sul-Americana de Nações (UNASUL), a Aliança Bolivariana para os Povos da América Latina (ALBA) e a Comunidade de Estados Latino-Americanos e Caribenhos (CELAC), correspondem, de distintas maneiras, aos conceitos de auto- 
nomia de Puig e Jaguaribe. Contudo, o que impede que avancem alguns desses processos é a vontade política, sendo o grau de compromisso dos atores fundamental. A esse respeito, Oszlak (2003) se pergunta: qual é a capacidade dos Estados latino-americanos para enfrentar a complexidade das tarefas que a integração regional exige?

Os processos de integração regional afetam os próprios âmbitos de atuação das instituições dos Estados nacionais envolvidos. A integração regional cria novas formas de intervenção ou penetração do Estado na sociedade, e, consequentemente, exige capacidades institucionais dos Estados para a implementação das medidas regionais nos territórios nacionais. Nesse sentido, assim como qualquer outra política pública, a integração regional exige que os Estados garantam certas condições de efetividade na sua implementação.

O autor nos alertará que da mesma forma em que é possível falar de uma agenda da integração, também existe uma outra agenda derivada do processo integracionista. Nos moldes da convergência de abordagens proposta neste trabalho, a primeira agenda (da integração) estaria mais vinculada com a estratégia política do bloco para enfrentar os constrangimentos internacionais históricos da América Latina, enquanto que a segunda agenda (decorrente da integração) se focaria nas medidas e ações institucionais necessárias para implementar as exigências do acordo integracionista, com impacto direto nas relações socioeconômicas dentro de cada país. Deste modo, trata-se de criar, no plano interno de cada Estado parte, as condições necessárias para o cumprimento das medidas tomadas no marco do processo de integração, incorporando-as nas agendas nacionais de implementação de políticas.

Ao incorporar uma "dimensão regional" à gestão governamental federal ou nacional, os Estados vêm-se obrigados a promover mudanças nas tecnologias de gestão e nas práticas administrativas, buscando equacionar suficiente pessoal capacitado e recursos materiais (financeiros, de infraestrutura e informáticos) adequados aos objetivos da integração. Segundo o autor, é importante salientar que cada política regional em particular exigirá capacidades de atuação diferenciais dos Estados, não sendo suscep- 
tíveis de generalização (Oszlak, 2007). Dessa forma, para fins de discutir a capacidade institucional de um Estado na implementação da integração regional deverão ser avaliados o objetivo específico e os meios nacionais para alcançar tais objetivos.

Dessa forma, fica clara a necessidade de sintonia entre os âmbitos interno e externo para a análise integral da integração regional. Não se pode perder de vista as conjunturas e funções do Estado no âmbito interno, bem como não é possível pensar em integração regional sem entender o contexto internacional e regional. Mais do que em qualquer aspecto, a leitura pela abordagem teórica aqui referida se faz necessária para entendermos para que lado a integração regional deveria caminhar, fazendo-se útil como instrumento de desenvolvimento interno e de inserção não subordinada no sistema internacional de países periféricos como os latino-americanos. Para além da análise de uma proposta de integração regional ideal para a América Latina, a abordagem aqui adotada nos chama a atenção acerca da importância de incorporar à análise da integração a questão das capacidades institucionais para sua implementação, a logística do relacionamento entre agências burocráticas nacionais e regionais, a sintonia entre as vontades políticas dos administradores nacionais, o desenho e o papel dos grupos de poder de cada Estado e como isso impacta na integração regional, dentre diversas possibilidades.

\section{CONSIDERAÇÕES FINAIS}

$\mathrm{Na}$ tentativa de propor um referencial teórico diferenciado, este trabalho colocou em diálogo diferentes abordagens sobre a natureza do Estado e de seu papel na sociedade. Como toda tentativa inicial, é nosso objetivo fomentar o debate sobre quais caminhos deve a integração regional na América Latina perseguir, a partir do momento em que entendemos o Estado autônomo como o mais adequado para guiar esse processo, tanto em âmbito interno quanto externo. Nosso objetivo último não se distancia dos autores latino-americanos clássicos das décadas de sessenta e seten- 
ta, sendo o desenvolvimento e a quebra da dependência em relação ao centro o que nos norteou durante toda a construção das discussões que embasaram o presente trabalho.

Nossa proposta do conceito ampliado de Autonomia, que parte do modelo bidimensional do Estado, estudado nas primeiras seções do trabalho, é o que liga o nosso entendimento das funções do Estado, no âmbito interno regulador e no âmbito externo condicionado, às possibilidades de superação do subdesenvolvimento e da dependência através da integração regional. Autonomia significa para nós que o Estado fortaleça suas capacidades para a efetiva implementação das políticas estatais, e para enfrentar as forças hegemônicas no âmbito internacional. Nesse contexto, a integração regional, enquanto instrumento de um Estado dotado de um projeto político adequado, deve ser capaz de impulsionar essa autonomia estatal a partir do momento em que busca mobilizar recursos e capacidades de poder, necessidade primária para combater qualquer relação de dominação.

Por fim, mantêm-se diversas questões em aberto, tanto da própria construção proposta quanto das que se ramificarão desta. A agenda de pesquisa da integração regional se enriquece a partir do momento em que novas propostas são colocadas na mesa. Assim, esperamos que, de alguma forma, discutir a integração regional a partir do modelo bidimensional do Estado seja produtivo ao campo de estudos.

\section{BIBLIOGRAFÍA}

Cardoso, Fernando Henrique e Enzo Faletto. Dependência e desenvolvimento na América Latina: ensaio de interpretação sociológica. Rio de Janeiro: Zahar, 1973.

Colacrai, Miryam. "Los aportes de la Teoría de la Autonomía, genuina contribución sudamericana. ¿La autonomía es hoy una categoría en desuso o se enfrenta al desafío de una renovación en un contexto in- 
terdependiente y más complejo?". Gladys Lechini, Victor Klagsbrunn e Williams Gonçalves (orgs.). Argentina e Brasil: vencendo os preconceitos. As várias arestas de uma concepção estratégica. Rio de Janeiro: Revan, 2009. 33-49.

Evans, Peter. Autonomia e parceria. Estados e transformação industrial. Rio de Janeiro: Editora UFRJ, 2004.

FURTADO, CELSO. Subdesenvolvimento e estagnação na América Latina. Rio de Janeiro: Civilização Brasileira, 1968.

Gingolani, LuCiana. "The State of State Capacity: a review of concepts, evidence and measures". Working Paper 13. Maastrich Graduate School of Governance. UNU-Merit, 2013. En http://www.merit.unu.edu/ publications/working-papers/abstract/?id $=5017$ (Data de consulta: 13 de julho de 2017).

Gourevitch, Peter. "The Second Image Reversed: The International Sources of Domestic Politics". International Organization 32. 4. (1978): 881-912.

Granato, LeOnardo. "Mercosur: Ideales y estrategias em la periferia del capitalismo". María A. Racovschik e Carlos Raimundi (orgs.). iFin de ciclo o paréntesis en la región? Balance de la última década y reflexiones sobre el nuevo escenario del MERCOSUR. Buenos Aires: FLACSO Argentina, 2016. 77-92.

NAHUEl OdDOnE e Matías BATTAglia. "Teoría de la autonomía: ¿aún vigente para analizar los procesos de cooperación en América Latina?". Teoria \& Pesquisa 25.1 (2016): 153-175.

GuerReIro RAmos, AlBerTo. Condições Sociais do Poder Nacional. Rio de Janeiro: Instituto Superior de Estudos Brasileiros, 1957.

IANONI, MARCUS. "Autonomia do Estado e desenvolvimento no capitalismo democrático". Revista de Economia Política 33.4 (2013): 577-598.

Jaguaribe, Helio. "Dependencia y autonomía en América Latina". Helio Jaguaribe, Aldo Ferrer, Miguel S. Wionczek e Theotonio dos Santos. La dependencia político-económica de América Latina. Buenos Aires: Siglo XXI, 1973.1-85. 
Desenvolvimento económico e desenvolvimento político. Rio de Janeiro: Paz e Terra, [1962] 1972.

Mann, MichaEL. "The Autonomous Power of the State: Its Origins, Mechanisms and Results". European Journal of Sociology/Archives Européennes de Sociologie 25.2 (1984):185-213.

Miliband, RAlPH. O Estado na sociedade capitalista. Rio de Janeiro: Zahar, 1972.

O'Donnell, Guiluermo. "Acerca del Estado, la democratización y algunos problemas conceptuales. Una perspectiva latinoamericana con referencias a países poscomunistas". Desarrollo Económico 33. 130 (1993):163-184.

"Apuntes para una teoría del Estado". Revista Mexicana de Sociología 40.4 (1978):1157-1199.

e Delfina LincK. Dependencia y autonomía. Formas de dependencia y estrategias de liberación. Buenos Aires: Amorrortu, 1973.

OsZLAK, OSCAR. "Estados capaces: un desafío de la integración". Bernardo Blejmar (comp.). Liderazgo y desarrollo sustentable. Buenos Aires: Ediciones Manantial, 2003. 119-160.

"Formación histórica del Estado en América Latina. Elementos teórico-metodológicos para su estudio". Carlos H. Acuña (comp.). Lecturas sobre el Estado y las políticas públicas. Retomando el debate de ayer para fortalecer el actual. Buenos Aires: Proyecto de Modernización del Estado, Jefatura de Gabinete de Ministros, [1978] 2007. 115-142.

e Guillermo O’Donnell. "Estado y políticas estatales en América Latina. Hacia una estrategia de investigación". Carlos H. Acuña (comp.). Lecturas sobre el Estado y las politicas públicas. Retomando el debate de ayer para fortalecer el actual. Buenos Aires: Proyecto de Modernización del Estado, Jefatura de Gabinete de Ministros, [1981] 2007. 555-587.

POULANTZAS, Nicos. Poder político y clases sociales en el Estado capitalista. México: Siglo XXI, [1968] 2007. 
Puig, Juan Carlos. Doctrinas internacionales y autonomía latinoamericana. Caracas: IAEAL/Universidad Simón Bolívar, 1980. "Integración y autonomía de América Latina en las postrimerías del siglo XX”. Integración Latinoamericana 109 (1986): 40-62.

REY, MaXimiLIANO. "Capacidad estatal y poder del Estado en Latinoamérica del siglo XXI: una perspectiva política para el análisis de las políticas públicas y la estatalidad". Revista Estado y Políticas Públicas 2 (2014):115-139.

SKOCPOL, THEDA. "Bringing the State Back In: Strategies of Analysis in Current Research". Peter Evans, Dietrich Rueschemeyer e Theda Skocpol (eds.). Bringing the State Back In. Nueva York/Cambridge: Cambridge University Press, 1985. 3-43.

Los estados y las revoluciones sociales. Un análisis comparativo de Francia, Rusia y China. México: FCE, [1979] 1984.

TILLY, CHARLES. Coerção, capital e estados europeus: 990-1992. São Paulo: Edusp, 1996. 